\title{
Perceptions of inevitability and demand for redistribution: Evidence from a survey experiment ${ }^{\text {is }}$
}

\author{
Miquel Pellicer $^{\mathrm{a}, \mathrm{d}}$, Patrizio Piraino ${ }^{\mathrm{b}, *}$, Eva Wegner $^{\mathrm{c}, \mathrm{d}}$ \\ a University of Duisburg-Essen, Germany \\ ${ }^{\mathrm{b}}$ University of Cape Town, South Africa \\ c University College Dublin, Ireland \\ d SALDRU, South Africa
}

\section{A R T I C L E I N F O}

\section{Article history:}

Received 31 January 2017

Received in revised form

19 September 2017

Accepted 16 December 2017

Available online 9 January 2018

\section{Keywords:}

Inequality

Demand for redistribution

\begin{abstract}
A B S T R A C T
Believing that inequality is inevitable may limit demand for redistribution. We explore this idea with a survey experiment in South Africa, one of the most unequal countries in the world. Inevitability beliefs can be influenced by learning about lower inequality elsewhere. We find that the demand for redistributive policies reacts to this information, while it is insensitive to other types of information/messages. Our analysis suggests a promising, and heretofore unexplored, avenue of research for refining our understanding of the determinants of demand for redistribution.
\end{abstract}

(c) 2018 Elsevier B.V. All rights reserved.

\section{Introduction}

The rise in inequality in numerous countries in recent decades has renewed academic interest in income redistribution. In the standard "median voter" framework, increasing inequality should lead to higher demand for redistribution and, ultimately, to more observed redistribution (Meltzer and Richard, 1981). Increasing or high levels of inequality would thus be tempered by consequently high redistribution that would prevent inequality from persisting at very high levels. Evidence in favor of such mechanism, however, has been scarce (Kenworthy and McCall, 2008; Kaufman, 2009). In fact, inequality has often been observed to persist at high levels, particularly in middle-income countries, giving rise to the concept of "inequality trap" (Bourguignon et al., 2007).

In response to these observations, a literature has emerged trying to renew our understanding of how levels of redistribution are determined. An important part of this literature has focused on the demand side: what factors explain preferences for redistribution? In a review article, Alesina and Giuliano (2011) survey several models and theoretical arguments from

\footnotetext{
is This research has received funding from the NOPOOR project under the FP7 of the European Commission (grant agreement \#290752). We would like to thank Martin Abel, Michael Carter, Nahomi Ichino, Ilyana Kuziemko, Ellen Lust, Jim Sallee, and Tim Smeeding for useful comments and suggestions. This is a revised version of a paper presented to the NYU-CESS Conference on Experimental Political Science; the UNU-WIDER conference on "Inequality measurement, trends, impacts, and policies"; the ERSA Political Economy workshop in Soweto, the Toronto Political Behaviour Workshop, the SITES-IDEAS meeting in Florence, the EPSA Annual Meeting, the Euro-African Conference in Marseille, the IMEBESS conference in Rome. We thank the participants at the above conferences as well as attendees at departmental seminars at the University of Bologna, University of California-Berkeley, University of CaliforniaDavis, University of Gothenburg, University of Pretoria, University of San Francisco, and University of Wisconsin-Madison. A supplemental appendix, along with the data and replication files, will be available in the online data warehouse of the NoPoor project (www.nopoor.eu).

* Corresponding author.

E-mail addresses: miquel.pellicer@uni-due.ie (M. Pellicer), patrizio.piraino@uct.ac.za (P. Piraino), eva.wegner@ucd.ie (E. Wegner).
} 
this literature. Starting with seminal explanations such as the role of expected upward mobility (Benabou and Ok, 2001), the authors examine a variety of factors from perceptions on the fairness of the income distribution, to political indoctrination and historical experiences affecting social norms, among others. ${ }^{1}$

A recent strand of research investigates the effects of inequality-related information on demand for redistribution with survey experiments. Cruces et al. (2013) and Karadja et al. (2017), for instance, analyse the effects of information about the respondent's true position in the income distribution. Kuziemko et al. (2015) provide information on changes in inequality over time within the United States. In general, these studies find that the effects of providing various types of information on redistributive demands tend to be small (Kuziemko et al., 2015), or to apply to specific groups in the population (Cruces et al., 2013; Karadja et al., 2017). ${ }^{2}$

We contribute to this recent line of research by exploring the consequences of providing information about inequality in an international perspective, as opposed to inequality within a single country. We test this via a survey experiment in South Africa, a country that has one of the highest Gini coefficients in the world. Our suggestion is that such information can influence redistributive preferences by affecting perceptions about the inevitability of inequality. Observing the (much lower) level of inequality in other countries ought to increase respondents' perception that very high inequality is not the norm-i.e. that high inequality is not inevitable.

Beliefs of inevitability can lead to inaction, as well as to attitudinal changes to reduce frustration and stress (Smith and Lazarus, 1990). In particular, poor individuals facing a situation of chronic inequality may become resigned and demobilized, demanding little redistribution as a way to cope with such situation. This type of mechanism is likely to be of particular importance in high inequality settings, like South Africa. In fact, we find that beliefs about the inevitability of inequality appear to be entrenched in our sample: more than half of respondents in our control group agree with the statement that the high levels of inequality in the country are inevitable. While we do not have comparable statistics from other countries, this seems to indicate an astounding pervasiveness.

The survey experiment was conducted in two waves (2014 and 2015) in three low-income townships of the Cape Town metropolitan area. In order to investigate the potential role of inevitability perceptions on redistributive preferences, both survey rounds include three core treatments. The first treatment shows information on "local" inequality: differences in income and asset ownership across various neighborhoods of Cape Town. This treatment is meant to capture the effect of information about inequality on redistributive preferences. The second treatment provides information on South African inequality in comparative perspective. The treatment shows how inequality is unusually high relative to other (including neighbouring) countries. This is a key treatment, which intends to affect inevitability beliefs. Indeed, we show that providing this information reduces the chances of answering that the high inequality in South Africa is inevitable by more than 10 percentage points.

In an attempt to further reduce the sense of inevitability, we also provided a sub-treatment with video messages of South African leaders on the need to fight inequality. These messages are shown to a random subsample after either the "international" or the "local" information treatment. The data reveal that this treatment did not significantly affect perceptions of inevitability. That is, the messages failed to manipulate our key attitudinal variable. ${ }^{3}$

Our results show that the "international" information treatment leads to an increase in the support for higher top taxes and for the introduction of a basic income grant. Providing "local" information, in contrast, does not affect redistributive policy preferences. Moreover, we find that this pattern is present in different subsamples (i.e. different population groups and waves). The fact that the "international" information affects both inevitability and redistributive preferences while the "local" information does not is consistent with the idea that inevitability can limit demand for redistribution. This pattern of results also alleviates concerns that the international information treatment works simply because respondents wish to agree or please the interviewer. The fact that policy preferences do not respond to the local information suggests that this explanation is less plausible.

As the treatments convey different information, we acknowledge the possibility that the estimated effects may relate to other aspects of the information provided. This is a limitation of our design that we try to address in a number of ways. First, we consider the possibility that individuals may be more misinformed about international inequality. In both treatments we ask respondents to guess the extent of inequality before showing the true value. We observe, if anything, that respondents underestimate inequality more in the local information arm. Second, during the 2015 wave, we provided an additional treatment with information on South African income inequality in the same format as the "international" treatment, but without the comparison to other countries. While smaller sample sizes do not allow conclusive inference, this treatment appears to have no impact on perceptions of inevitability or on redistributive preferences. This suggests that it is the mere fact of putting South African inequality in comparative perspective that affects these outcomes. Third, being exposed to information on South African inequality in comparative perspective could trigger thoughts on the exceptionality of South

\footnotetext{
1 Tausch et al. (2013) review the experimental (laboratory) evidence on preferences for redistribution, with a focus on lessons that can inform the design of pension and social insurance schemes. Similar to Alesina and Giuliano (2011), their paper covers several determinants of demand for redistribution: these include altruism, prevailing views about the source of inequality (merit vs. luck), and self-serving biases.

2 Cruces et al. (2013) find an effect for over-estimators. Karadja et al. (2017) report a negative effect for under-estimators, but only for those with baseline right-wing ideology.

${ }^{3}$ We speculate that this likely reflects low levels of source credibility (Druckman, 2001).
} 
African legacy of racial inequality. This may lead in turn to an activation of historical grievances that could drive demand for more redistribution irrespective of feelings of inevitability. Inspecting two distinct post-treatment questions regarding race we find no evidence that the international treatment triggers racial considerations.

It is of course still possible that providing information on the much lower inequality in other countries affects some other unobserved factor that correlates with both inevitability and redistributive preferences, but we are at least able to exclude some prominent alternative explanations. At a minimum, our experiment points to the relevance of inevitability beliefs for understanding demand for redistribution. This, we hope, will open the way for further investigations on this unexplored mechanism in this literature.

The rest of the paper is organized as follows. Section 2 gives a short background of inequality and demand for redistribution in South Africa. Section 3 describes the survey experiment and its design. Section 4 presents the data and descriptive statistics, while Section 5 shows the results. Section 6 provides a brief discussion and Section 7 concludes.

\section{Inequality and demand for redistribution in South Africa}

South Africa is one of the most unequal countries in the world. One might expect redistribution to be high in postApartheid South Africa considering that the origins of present-day inequality lie in a colonial history and Apartheid institutional arrangements where a white minority enriched itself by denying political and economic rights to a black majority.

The African National Congress (ANC) came to power after the end of Apartheid, and has governed with large majorities for the past two decades. For the most part, ANC's social policies have focused on the rolling out of social grants, such as the old age pension and the child support grant, on which a large fraction of the population depends to make ends meet. Fiscal redistribution is, however, only slightly above the relatively low Latin American levels (Leibbrandt et al., 2011). ${ }^{4}$

Income inequality has not decreased since the advent of democracy (Leibbrandt et al., 2010). Moreover, inequality continues to follow the Apartheid pattern with the white minority predominantly occupying the top decile, followed by the Indians, the Coloureds, and the African blacks at the bottom. From the point of view of low-income South Africans, high inequality may thus appear entrenched. Not only inequality has had little traction in the policy domain, but it has also remained virtually unchanged since the democratic transition. ${ }^{5}$

Against this background of exceptionally high (and persistent) inequality, one might expect to observe high levels of demand for redistribution amongst the majority of South Africans. However, inspecting a few variables from the 2007 World Value Survey that are typically used in cross-country studies on demand for redistribution reveals that South African demand is generally comparable to the global average. ${ }^{6}$

Although an increasing number of service delivery protests suggests dissatisfaction with government performance (Alexander, 2010; De Juan and Wegner, 2017), such dissatisfaction appears to have not translated into an increased demand for redistribution. This mixed picture was also confirmed in focus group discussions that were carried out by the authors between June and October 2012 in preparation for this study. Although respondents were generally disappointed by the small economic returns of the democratic transition, they largely demanded jobs from the government, not redistribution through progressive taxation.

\section{The survey}

\subsection{Data collection}

The data presented in this paper originate from a survey of 2445 respondents in three low-income townships of the Cape Town metropolitan area. A first sample of 1644 respondents was interviewed in March and April 2014-just before the South African general elections in that year. A new sample of 801 respondents were administered the same questionnaire in March 2015. Across the two rounds, 1731 respondents were surveyed in Khayelithsa, an overwhelmingly 'African Black' township, while the rest of the survey was conducted in Delft (434 respondents in 2014) and Mitchell's Plain (280 respondents in 2015), which are mostly 'Coloured' areas.

The overall goal of the survey was to obtain a sample of South Africans from an urban low-income setting. While representativity was not a key concern, we tried to avoid an overly peculiar sample by randomly drawing a set of Enumeration

\footnotetext{
4 Leibbrandt et al. (2011) find that taxes and transfers decreased the Gini coefficient by around 5 points, which is only slightly higher than redistribution in several Latin American countries, where the average is 2 percentage points (Goñi et al., 2011). In contrast, the figure in Europe is close to 20 (Goñi et al., 2011)

5 Only since 2013, there has been a growing discussion in the ANC leadership regarding the need for a "second transition", implying that the transition in 1994 had been a political transition only. Partly, this is due to the emergence of the "Economic Freedom Fighters" (EFF), a new party founded in 2013 by Julius Malema. The EFF questions the post-Apartheid economic policies and demands the nationalization of mines as well as the redistribution of land without compensation. In the 2014 general elections, the EFF won 25 seats in parliament (out of 400) with around 1 million votes.

6 The questions we reviewed in the World Value Survey elicit respondents' view on (i) whether incomes should be made more equal; (ii) whether the government should take more responsibility to ensure that everyone is provided; and (iii) whether taxing the rich is an essential characteristic of democracies.
} 
Areas (EAs) in the three townships. We then let fieldworkers choose every 12th house in a random walk in the EA, which have around 200 households each. In Khayelitsha, EAs were stratified by type of housing: formal vs. informal (e.g. shack dwellers).

An English language questionnaire was developed first and was then translated into Xhosa and Afrikaans. Respondents could choose the questionnaire language at the beginning of the interview, which lasted between $25-30$ min. ${ }^{7}$ Survey responses were captured on mobile devices and directly transmitted to the server after the completion of the interview together with the GPS location. This allowed for an immediate check of the accuracy of the interview location and monitoring of data quality.

The questionnaire begins with a number of standard socio-demographic questions (household size, employment etc. . .) administered to all respondents. Random subsets of the sample are then exposed to different types of information/messages, which constitute our treatment arms. The third part of the questionnaire is again administered to all participants and it contains our main outcome variables as well as additional demographic questions.

\subsection{Treatments}

Both waves of the survey had three identical core treatments. The first two treatments provided visual information on inequality in South Africa in a (i) local and (ii) internationally comparative perspective. The survey also provided a subtreatment with video messages of political leaders on the need to fight inequality. These speeches are given in addition to either the "international" or the "local" information. An overview of the survey design is presented in Appendix A Fig. A1.

\subsubsection{Local information treatment}

This treatment presents information on differences between neighbourhoods in Cape Town, known to local residents as comparatively rich or poor areas. The idea is that a certain number of respondents might underestimate the size of the income gap between the rich and the poor in their city and that updating their beliefs may lead to greater concern about inequality. In a first step, participants were asked to guess the median income in a typically rich neighbourhood of Cape Town in comparison to typically poorer areas. Subsequently, they were shown the correct figures for all areas. In a second step, differences in ownership of assets (such as computers, washing machines etc.) in these neighbourhoods were displayed. ${ }^{8}$

The aim was to inform participants about the high levels of inequality between neighbourhoods. We did not include the respondent's own neighbourhood in this information as the objective was not to think about one's own individual situation but about inequality more generally. Fig. 1 illustrates an example of this treatment. The exact wording used in the questionnaire is provided in Appendix B.

\subsubsection{International information treatment}

This treatment presents inequality in South Africa in comparison to other countries. We will refer to this as the "international" treatment. It shows the rich-poor ratio in South Africa, as well as in some other developing and high-income nations. Importantly, it includes some of South Africa's neighbouring countries and shows that South Africa's rich-poor ratio is by far the worst among the group presented. The treatment is constructed so that respondents first see the rich-poor ratio in different countries in form of a ladder and then are asked to guess the ladder's length for South Africa. The last screen then shows the correct ladder for South Africa as in Fig. $2 .{ }^{9}$ The exact wording used in the survey is provided in Appendix B.

Comparing inequality to the much lower levels elsewhere is intended to suggest that South Africa's inequality is exceptional, and not a common occurrence (i.e. a "fact of life"). By providing this information, we intended to positively affect perceptions of changeability of inequality, with a potential effect on demand for redistribution.

During the 2015 wave, we interviewed a further 153 respondents that were exposed to a type of information treatment that had the same format as the international treatment, but no comparison to other countries was given. Despite the low statistical power on this additional arm, we will report the treatment effects when discussing the plausibility of alternative interpretations of our main empirical findings in Section 6.

\subsubsection{Video messages}

A sub-branch of the experimental design takes the form of elite support for redistribution. We operationalize this with video speeches by members of the South African political elite. One message is by the president Jacob Zuma while the second is by Julius Malema, the leader of a new party founded in the early 2010 s (Economic Freedom Fighters). Note that

\footnotetext{
7 English, Xhosa, and Afrikaans are the most common languages in the Western Cape. A back translation was done with the feedback from fieldworkers. The surveyors' population group corresponded to that of the respective interviewees.

8 We initially programmed the randomisation to have a proportionally higher incidence of the local information treatment to allow for a comparison of effects across three different combinations of neighbourhoods. About half-way through the first wave, it became clear that the neighborhood comparison did not matter and we opted for increasing power on the international treatment by re-programming its incidence in the mobile devices. This change will be controlled for in each of the regressions in the empirical section below. See Appendix A Fig. A1 for the final sample sizes by treatment status.

${ }^{9}$ An initial screen defined the meaning of the ladders shown. Rich-poor ratios were calculated using data from the 2007-2008 Human Development Report by the UNDP. They refer to the 80:20 income percentile ratios.
} 


\section{Monthly Income}

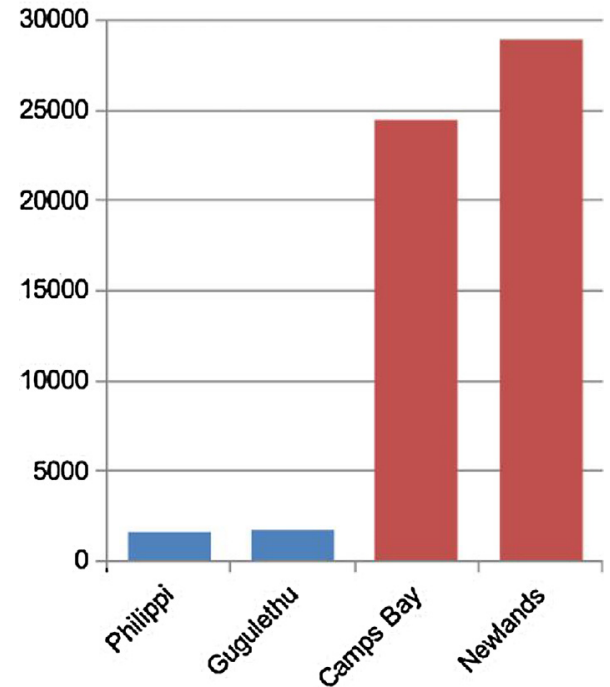

Fig. 1. Example of local treatment.

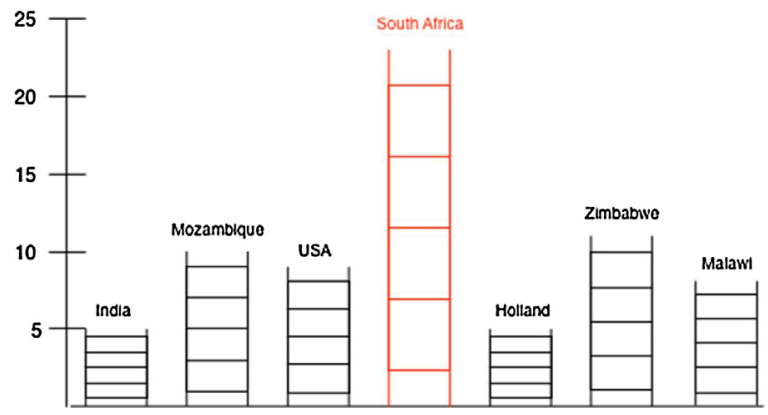

Fig. 2. International treatment.

each respondent is randomly presented with only one video. Overall, we do not observe speaker-specific effects and treat the videos as a single sub-treatment. ${ }^{10}$

The speeches are shown after either the "international" or the "local" information treatment. By showing elite support for redistribution, the video messages were intended to affect perceptions of changeability. Seeing that elites speak against inequality may lead respondents to believe that redistribution is a priority amongst policymakers. The hypothesis was that these messages would amplify any effect from the information treatments.

\section{Data}

\subsection{Descriptive statistics}

Table 1 shows some descriptive statistics for the different sample areas compared to data from the 2011 population Census, where available. As shown in Table 1, the key difference between our samples and the Census statistics in these areas is the larger number of women and unemployed amongst our respondents. This is likely due to men being more likely to be employed and absent from the dwelling during daytime. Although fieldworkers were asked to schedule appointments with the absent person in the household (if randomly selected for the interview by the mobile device), they were only asked

\footnotetext{
10 The videos were available either in English (the original version) or in dubbed Xhosa/Afrikaans versions to the participants. In the first wave of the survey, one sub-branch of this treatment provided an additional speech by Archbishop Desmond Tutu (a total of 190 participants saw this video). A decision was made not to include Tutu's video in the second wave as a result of feedback form the field, which indicated that his message was not seen as a form of elite support for redistribution.
} 
Table 1

Demographic characteristics by area.

\begin{tabular}{|c|c|c|c|c|c|c|}
\hline & \multicolumn{2}{|c|}{ Khayelitsha } & \multicolumn{2}{|l|}{ Delft } & \multicolumn{2}{|c|}{ Mitchell's Plain } \\
\hline & Sample & Census 2011 & Sample & Census 2011 & Sample & Census 2011 \\
\hline Female & 0.60 & 0.51 & 0.64 & 0.51 & 0.67 & 0.51 \\
\hline Employed & 0.31 & 0.40 & 0.42 & 0.38 & 0.18 & 0.42 \\
\hline Mean age & 37 & & 40 & & 45 & \\
\hline Matric & 0.30 & 0.35 & 0.22 & 0.19 & 0.20 & 0.18 \\
\hline Informal housing & 0.56 & 0.55 & 0.15 & 0.15 & 0.04 & 0.04 \\
\hline Government grants & 0.39 & & 0.33 & & 0.53 & \\
\hline $\mathrm{N}$ & 1731 & & 434 & & 280 & \\
\hline
\end{tabular}

Notes: The sample in Delft includes only sub-places with a predominantly Coloured population. The Census figures, in contrast, are based on information on all Coloureds in Delft. The Mitchells Plain sample was drawn from relatively lower-income areas.

Table 2

Key outcome variables in the control group.

\begin{tabular}{lcc}
\hline & Total & Wave 1 \\
\hline Attitudes & & Wave 2 \\
$\quad$ Inequality problem & 0.91 & 0.89 \\
$\quad$ Inequality inevitable & 0.54 & 0.53 \\
Policy preferences & & 0.94 \\
Support for... & 0.07 & 0.04 \\
$\quad$ Progressive top tax & 0.64 & 0.61 \\
$\quad$ Basic income grant & 0.36 & 0.33 \\
$\quad$ Higher general tax & & 0.11 \\
Actions (progressive or regressive) & 0.74 & 0.68 \\
$\quad$ Petition & 0.58 & 0.38 \\
$\quad$ SMS intended & 0.23 & 0.44 \\
$\quad$ SMS sent & 0.83 & \\
\hline
\end{tabular}

Notes: All variables are coded as dummy variables except otherwise stated. "Progressive top tax" is coded as one, zero, and minus one if respondent wishes this tax increased, unchanged, and decreased, respectively. "SMS intended" refers to respondents stating that they would send an SMS, while "SMS sent" to those actually sending it.

to return to the house prior to sunset for security reasons. The fraction of high school graduates (matric) is roughly in line with the Census and so is the share of informal housing.

\subsection{Outcome variables}

Table 2 shows the descriptive statistics for key outcome variables in the control group in the pooled sample and by survey wave. Outcomes include attitudes towards inequality, policy preferences, and "action" outcomes (where respondents could transmit their redistributive preferences to local politicians). Unless otherwise stated, variables are coded as binary variables so that the values in Table 2 represent the shares favouring a certain position/action. The exact wording of these outcome questions as well as the full list of post-treatment questions is provided in Appendix C.

Attitudinal outcomes include a question on whether inequality in South Africa is seen a serious problem, as in Kuziemko et al. (2015). ${ }^{11}$ Importantly, we also ask respondents whether the high level of inequality in South Africa is seen as inevitable (as opposed to "could be made smaller"). This is a core question, which is meant to capture perceptions of "changeability".

Tax policy preferences are elicited through questions about the respondents' support for three hypothetical policy changes: (i) an increase/decrease in the top marginal tax rate, ${ }^{12}$ coded as $-1,1$, or 0 if the respondent supports reducing, increasing, or leaving the rate unchanged, respectively; (ii) the introduction of a universal basic income grant; (iii) a general increase in taxation for all income groups to improve public infrastructures such as schools, roads and sanitation.

Action outcomes include the option to send an SMS (at a real cost) or to sign an online petition on the surveyor's tablet. Both the petition and the SMS were pre-populated and allowed respondents to express their support (or disapproval) of tax increases for the rich and of the introduction of a basic income grant. While both actions bear a cost - the petition the cost of exposing oneself by signing one's name, the SMS the material cost of sending the message - the item was randomized

\footnotetext{
11 The question is identical to theirs with one exception: we replaced the word inequality with "gap between rich and poor" throughout the survey. This is because a pilot showed that a large fraction of respondents confused the word inequality with equality, partly as a result of non-unique renditions of the word in the local languages.

12 The group of top earners starts with around 60,000 ZAR (about 5000 USD at the time of the survey) per month. As the concept of top marginal tax rate may be difficult to grasp, the question provides a simplified example (see Appendix $C$ for exact wording).
} 
Table 3

Attitudes towards inequality.

\begin{tabular}{lll}
\hline & 1. Inequality problem & 2. Inequality inevitable \\
\hline Local Info & $0.025(0.016)$ & $-0.015(0.029)$ \\
Local Info + Video & $0.015(0.017)$ & $-0.023(0.033)$ \\
International Info & $0.045^{* * *}(0.015)$ & $-0.112^{* * *}(0.032)$ \\
International Info + Video & $-0.013(0.019)$ & $0.052(0.041)$ \\
Control mean & 0.91 & 0.54 \\
Covariates & Yes & Yes \\
Obs. & 2385 & 2124
\end{tabular}

Notes: Robust standard errors in parentheses. Significance: ${ }^{* *} 0.01 ;{ }^{* *} 0.05 ;{ }^{*} 0.10$. Outcomes are dummy variables.

so as to avoid the possibility of virtually all respondents choosing the petition (as this was free of charge). Moreover, we distinguish between those saying that they would send an SMS and those actually sending it. ${ }^{13}$

Some interesting patterns emerge from the statistics shown in Table 2. The first noticeable insight is the very high share (around 90\%) agreeing with the statement that inequality is a serious problem in South Africa. As a comparison, Kuziemko et al. (2015) find a control group mean of $28 \%$ stating that inequality is a serious problem in the United States. The fact that inequality in the country is something the vast majority of our respondents consider to be seriously problematic provides an interesting baseline scenario compared to previous surveys utilizing this question.

The very high level of concern about inequality does not seem to translate in high shares of respondents who want to increase taxes for the rich. This suggests that concerns about inequality may not be sufficient to generate redistributive tax preferences. In contrast to taxes, support for the basic income grant is much higher.

Regarding the action outcomes, the overall large share of respondents willing to take any form of action (either favouring or opposing the policy change) is remarkable. This suggests that the actions proposed by the survey resonate with respondents. The willingness to sign a petition is substantially higher compared to sending an SMS. This could be a result of either the material cost associated with this action or the difference in action "type". ${ }^{14}$ The gap between the intention to send an SMS to express policy preferences and the actual transmission is also noticeable, highlighting the importance of introducing measurable behavioural outcomes in survey experiments.

Finally, Table 2 shows some noteworthy (and statistically significant) differences in the control group means across the two waves of the survey. The largest differences are in the action outcomes, with the willingness to act being much higher in the 2015 survey for all types of actions. The lower figures in 2014 could be related to the survey taking place in the heat of an election campaign, with respondents possibly being more careful or suspicious about getting in contact with politicians.

\section{Results}

We estimate treatment effects on four treatment dummies: local information, local information plus video, international information, international information plus video. These regressions include controls for age (quadratic), gender, formal dwelling, completion of matric, employment, and receipt of government grants. We also include fieldworker fixed effects, wave and area dummies. When the outcomes are binary, regressions are performed using a linear probability model. Treatment variables are coded so that the coefficients on the video variables are to be interpreted as the effect of the video in addition to that of the respective information treatment, which is in turn given by the coefficient on the information dummies.

As randomization was programmed into the mobile devices used for the survey, we should have a priori confidence in the success of the random treatment allocation. Table A1 in Appendix A shows that this is indeed the case. The various columns present the coefficients from regressing different socio-economic variables on the treatment dummies. None of the differences between the respondents in the various treatment arms and the control are significant at the five percent level.

\subsection{Attitudes}

The treatment effects on attitudes towards inequality are shown in Table 3 . The coefficient estimates in Column 1 show that information on inequality in both local and international perspectives generates an increase in the degree to which respondents view inequality as a serious problem, although the effect does not reach conventional significance levels for the local information treatment. This result seems remarkable considering the very high control group mean for this variable in our sample.

The most relevant results for our purposes concern the inevitability of inequality (Column 2). While local information on inequality does not affect perceptions of inevitability, the international treatment does, and very strongly so. Respondents are

\footnotetext{
13 The SMS was sent to a phone number belonging to the survey company with the indication that we would let local representatives know what share of our respondents were supporting certain policies.

14 A petition can be seen as a civil society type of action whereas the SMS possibly requires a higher level of trust in politicians.
} 
Table 4

Policy preferences.

\begin{tabular}{|c|c|c|c|c|}
\hline & 1. Progressive top tax & 2. Basic Income Grant & 3. Higher general tax & 4. Summary index \\
\hline Local Info & $0.020(0.037)$ & $-0.010(0.025)$ & $-0.021(0.026)$ & $-0.036(0.056)$ \\
\hline International Info & $0.091^{* *}(0.042)$ & $0.054^{* *}(0.027)$ & $0.032(0.029)$ & $0.186^{* * *}(0.064)$ \\
\hline Control mean & 0.07 & 0.64 & 0.36 & 0.03 \\
\hline Covariates & Yes & Yes & Yes & Yes \\
\hline Obs & 2180 & 2338 & 2363 & 2073 \\
\hline
\end{tabular}

Notes: Robust standard errors in parentheses. Significance: ${ }^{* * *} 0.01$; $^{* *} 0.05 ;{ }^{*} 0.10$. The summary index is obtained by first standardizing each outcome (by subtracting its mean and dividing it by its standard deviation) and then summing the three standardized variables and divide by the standard deviation of the sum (to obtain an index that has a standard deviation of 1 ).

11 percentage points less likely to think that high inequality in South Africa is inevitable after seeing the much lower income gaps in other countries. We can easily reject equality of this coefficient with all other treatment effects. Thus, exposure to internationally comparative information successfully affects perceptions on the changeability of high inequality in South Africa.

Seeing the video messages of politicians condemning inequality, on the other hand, has no significant effect on attitudes towards inequality. In particular, the video messages fail to further reduce inevitability perceptions, which was the intention of our design. Given that the sub-treatment did not successfully manipulate our key attitudinal variable, we will focus on the main information treatment effects in the remainder of the analysis. ${ }^{15}$

\subsection{Policy preferences}

Table 4 shows the treatment effects on the three policy variables defined above: progressive top tax rate, basic income grant, and general tax increase. We also aggregate the information across these three variables into a standardized index in order to examine the general pattern of results. ${ }^{16}$

The table shows that the local information treatment has no effect on general redistributive preferences, while the international treatment has a positive effect on supporting a more progressive top marginal tax rate and the introduction of the basic income grant. The international treatment effect is also positive and significant on the summary index. Table 4 provides a key result of this paper. Providing information about the much lower inequality elsewhere increases the demand for these redistributive policies. In contrast, providing information about local inequality does not affect these policy preferences. ${ }^{17}$

Taken together, the estimates in Tables 3 and 4 support the idea that preferences for redistributive policies are related to views about the inevitability of inequality. This is consistent with the literature on the importance of changeability perceptions for counteracting attitudes of status quo preservation.

\subsection{Robustness}

It is important to check whether our basic result applies with some generality or is instead driven by a specific group or context. This section thus examines treatment effects by population group and survey wave. We focus on two main variables: perceptions of inevitability, and the summary index of redistributive demands.

The main results appear to apply quite generally (Table 5). The estimated effects on the local information treatment are statistically insignificant in all groups and always smaller in absolute value compared to the international treatment. For the two population groups and for the two waves, the international treatment decreases inevitability perceptions and increases demand for redistribution. The magnitude of the coefficients is very similar for African Blacks and for Coloureds. Coefficients on the international treatment are higher in absolute value for Wave 1 than for Wave 2, but we cannot reject equality of estimates across waves. Interestingly, this pattern applies to both inevitability perceptions and demand for redistribution. That is, the subgroup that reacts less to the international treatment in terms of inevitability, does so also in terms of demand for redistribution.

The comparison between sub-groups confirms the main empirical pattern we highlight in this paper: whenever a treatment affects views on the inevitability of high levels of inequality in South Africa, redistributive preferences are affected in a consistent way. The finding that our results apply to different groups should also alleviate concerns about multiple

\footnotetext{
15 The full set of coefficient estimates (including sub-treatment effects) are reported in the Supplemental online Appendix. The effects of the video messages on the various outcomes are generally insignificant, though inevitability perceptions always negatively co-vary with support for redistributive policies.

${ }^{16}$ Following Chetty et al. (2011), we first standardize each outcome by subtracting its mean and dividing it by its standard deviation. We then sum the three standardized variables and divide by the standard deviation of the sum to obtain an index that has a standard deviation of 1 (see also Kling et al., 2007 ; Clingingsmith et al., 2009; for similar approaches). As explained in these papers, the summary measure aggregates information about related constructs. The idea is to detect effects that go in the same direction within a domain, not to suggest that the components within a domain are proxies for a single latent factor.

17 We can reject equality of coefficients between the local and the international treatment effects in Columns 2 and 4 at the $5 \%$ and $1 \%$ level respectively.
} 
Table 5

Basic results by subgroup.

\begin{tabular}{llllll}
\hline & All & African Black & Coloured & Wave 1 & Wave 2 \\
\hline$\quad \begin{array}{lllll}\text { Inequality Inevitable } \\
\quad \text { Local Info }\end{array}$ & $-0.015(0.029)$ & $-0.010(0.036)$ & $-0.023(0.050)$ & $-0.035(0.033)$ & $0.038(0.064)$ \\
$\quad$ International Info & $-0.112^{* * * *}(0.032)$ & $-0.111^{* *}(0.040)$ & $-0.109^{*}(0.053)$ & $-0.160^{* *}(0.047)$ & $-0.073^{*}(0.044)$ \\
$\quad$ & & & & \\
$\quad$ & $-0.077(0.068)$ & $0.103(0.094)$ & $-0.054(0.065)$ & $0.101(0.118)$ \\
$\quad$ Local Info & $-0.036(0.056)$ & $0.199^{* *}(0.078)$ & $0.171(0.107)$ & $0.284^{* *}(0.100)$ & $0.158^{* *}(0.081)$ \\
$\quad$ International Info & $0.186^{* * *}(0.063)$ & 1442 & 604 & 1319 & 754 \\
N & 2073 &
\end{tabular}

Notes: Robust standard errors in parentheses. Significance: ${ }^{* * *} 0.01 ;{ }^{* *} 0.05 ;{ }^{*} 0.10$

Table 6

Action outcomes.

\begin{tabular}{|c|c|c|c|c|c|c|}
\hline & \multicolumn{3}{|l|}{ Top tax } & \multicolumn{3}{|l|}{ BIG } \\
\hline & Petition & SMS intended & SMS sent & Petition & SMS intended & SMS sent \\
\hline Local Info & $0.032(0.039)$ & $0.033(0.033)$ & $0.016(0.022)$ & $-0.038(0.052)$ & $-0.017(0.045)$ & $-0.007(0.035)$ \\
\hline International Info & $0.101^{* *}(0.050)$ & $0.076^{* *}(0.037)$ & $0.022(0.023)$ & $0.069(0.058)$ & $0.049(0.053)$ & $-0.005(0.037)$ \\
\hline Covariates & Yes & Yes & Yes & Yes & Yes & Yes \\
\hline Control mean & 0.03 & 0.05 & 0.01 & 0.48 & 0.40 & 0.13 \\
\hline Obs & 1154 & 1107 & 1107 & 1154 & 1107 & 1107 \\
\hline
\end{tabular}

Notes: Robust standard errors in parentheses. Significance: ${ }^{* * *} 0.01 ;{ }^{* *} 0.05 ;{ }^{*} 0.10$. Action outcomes assign value one (minus one), if action is progressive (regressive), and zero otherwise. "SMS intended" refers to respondents stating that they would send an SMS, while "SMS sent" to those actually sending it. BIG denotes basic income grant.

hypotheses testing. If the significance of the estimates in the full sample were the result of chance, we would not expect to see robustness across sub-groups.

Finally, we directly regress the summary index of redistributive demands on perceived inevitability in the control group. This estimation delivers a negative and significant (at $5 \%$ confidence level) coefficient of -0.155 . This suggests that the negative co-variance between inevitability and demand for redistribution exists outside the experimental framework.

\subsection{Actions}

An additional goal of the survey was to evaluate respondents' willingness to bear a cost to act upon their preferences. To this end, two possible actions were introduced. Respondents were randomly offered to either sign a petition or send an SMS regarding the increase in the top marginal tax rate and the introduction of a basic income grant. We construct different outcome variables by action type (petition, intended SMS, sent SMS) and policy (top tax, basic income grant). Table 6 shows the treatment effects on variables capturing the progressivity of the action considered. ${ }^{18}$ As mentioned in Section 4 , the sample sizes for these outcomes are halved, because respondents received the option of implementing either an SMS or a petition.

Consistent with the treatment effects on redistributive preferences, the international information is the only treatment that has some significant effects on behavioral outcomes. The treatment significantly increases respondents' willingness to sign a petition and their intention to send an SMS regarding their top tax preference. Concerning the BIG, the coefficients on the international treatment are still positive, and of relatively high magnitude, but they are not statistically significant. For neither policy, however, there is an effect on actually sending an SMS.

The effect of the international information on some of the action outcomes suggests that the changed preferences are "real", in the sense that respondents want to follow up on their preferences with politicians. As argued above, petitions while free of charge from a material point of view - are not without cost as respondents are disclosing their name. At the same time, the lack of an effect on actually sending the SMS shows that these effects may not carry over to materially costly actions. While fully acknowledging this caveat, we believe that the results for action outcomes - with the effects of the international treatments on a subset of outcomes and the general consistency between attitudinal and behavioral outcomes - are overall supportive of the robustness of our main findings. ${ }^{19}$

\footnotetext{
18 These variables take the value of zero for respondents who do not want to take an action, -1 for those wanting to take an action to transmit a regressive message (decrease taxes for the rich, not introduce the BIG) and 1 for those wanting to take an action to transmit progressive preferences (increase taxes for the rich, introduce the BIG).

${ }^{19}$ We explored different definitions of the action outcomes-i.e. by aggregating across issues (BIG and top tax) or disaggregating by progressive/regressive content. The international information is the only treatment that consistently displays at least some significant effects in any categorization.
} 


\section{Discussion}

Our empirical analysis contributes to a growing literature in economics that seeks to understand the role of different types of information about inequality on demand for redistribution (Kuziemko et al., 2015; Cruces et al., 2013, Karadja et al., 2017). Karadja et al. (2017) note that this literature, which focuses solely on within-country information about inequality, provides mixed results (p.202). Similarly, we find that providing information on local inequality in South Africa has no clear effects on support for redistributive policies. The main novelty in our paper, however, is the design of an information treatment that compares levels of inequality across countries. We show that this type of information has positive and significant effects on support for redistributive policies.

We suggest that this result is related to individuals' perceptions about the inevitability of inequality. By providing information on the high inequality in South Africa relative to other countries, the treatment suggests that such high disparities are not the norm-i.e. that high inequality is not inevitable. Indeed, the data show that inevitability perceptions are successfully manipulated by the international information treatment. The finding that support for redistributive policies only reacts to the treatment that successfully manipulates inevitability perceptions (while being insensitive to other types of information) points to inevitability beliefs as a potential determinant of demand for redistribution. This, we believe, should warrant further investigations of this overlooked mechanism in the economics literature. ${ }^{20}$

The idea that perceptions of changeability/inevitability ought to affect decision-making is straightforward. An individual facing the possibility to engage in mobilization against inequality will be more inclined to do so the higher the probability of success. In the extreme, if inequality is perceived as inevitable, such course of action would not be rational. In addition, perceptions of inevitability can have psychological effects beyond this straightforward mechanism; effects that in turn serve to cement such inaction. The key to these effects is the notion of "coping"; i.e. how individuals cope with difficult, stressful or problematic situations. Perceiving that inequality is inevitable and cannot be changed leads to psychological reactions ranging from becoming "resigned", to justifying existing inequalities as coping mechanisms. These ideas are well grounded in the field of psychology (see Folkman and Moskowitz, 2004; Smith and Lazarus, 1990).

In particular, a strand of literature within social psychology has provided evidence on the link between perceptions of changeability and preferences about social arrangements. The theory of "System Justification" argues that disadvantaged individuals may engage in a form of belief-altering emotional coping that involves justifying and even legitimizing the status quo (Jost et al., 2003; Jost et al., 2004). Studies within this literature have shown that system justification and beliefs of changeability and efficacy are linked. For instance, in a recent contribution, Johnson and Fujita (2012) show that when individuals believe that the system can be reformed they will try to improve or challenge the status quo, as opposed to justifying it (see also Van der Toorn et al., 2015). ${ }^{21}$

While we believe that perceptions of inevitability can explain the differential effects of our treatment manipulations, we acknowledge that our international information treatment might generate reactions other than those relating to inevitability. This, in turn, may affect demand for redistribution in the observed direction. A first concern, common to survey experiments in different settings, is that respondents may feel compelled to "please" the researcher/fieldworker. However, the finding of no treatment effect for the local inequality information would seem to rule out this possibility. Secondly, it is possible that at baseline individuals are relatively more knowledgeable about local income disparities compared to international inequality. To explore this, we asked respondents in each treatment to guess the respective level of inequality before providing the information. Comparing guesses with the actual values, we find that the overwhelming majority of respondents underestimated inequality in both treatments. For the international treatment, 85\% of respondents underestimated the level of inequality, with the average guess being about $40 \%$ below the mark. For the local treatment, $94 \%$ of respondents underestimated the gap ratio between rich and poor neighborhoods, with an average guess that was $70 \%$ below the true value. These figures indicate that it is unlikely that the effect of the international treatment on inevitability and redistributive preferences is driven by a higher degree of belief updating. 22

An additional concern is that the local and the international treatments differ in the format and type of the information provided-i.e. histograms on neighborhood differences vs. ladders on rich-poor individuals in the country. While it is not $a$ priori obvious why such difference in layout could lead to the observed results, we attempted to address this limitation by interviewing a further 153 individuals in 2015. These respondents were exposed to a new treatment that is identical to the international treatment, except that no comparison to other countries was given. The concept of the rich-poor ratio is initially explained with a ladder, after which respondents are asked to guess the value of the ladder for South Africa. The actual length of the ladder is then shown. Guesses provided by respondents suggests a similar processing of this new treatment to that

\footnotetext{
20 The type of mechanism examined in this paper has recently been shown to be relevant for political behavior. In a context where corruption is high or expectations on politicians are low, providing information on politicians (mal)performance or corruption is in itself insufficient to affect behavior. In contrast, information on better performance elsewhere can affect the willingness to change the status quo (see Gottlieb, 2016; Bauhr and Grimes, 2014).

21 Trump (2017) uses experimental evidence to argue that living in an unequal environment may make people systematically more likely to think of inequality as a legitimate outcome. This appears to occur at least in part because people are motivated to believe that their social system is fair.

22 This is further supported by feedback from fieldworkers documenting that respondents in the two treatments reacted similarly to the 'visual effect' of being shown the correct length of the bar after their guesses.
} 
of the international information treatment. ${ }^{23}$ Table A2 in Appendix A reports the estimated effects of exposure to this new type of information on our key outcome variables using only the 2015 wave. For comparison, we also report the treatment effects of the international information on the same sample. While the sample size receiving the additional treatment is low and the coefficients imprecisely estimated, the point estimates in Table A2 suggest that this information has limited effect on inevitability and redistributive preferences. ${ }^{24}$ In addition, unlike the international treatment, there is no evidence of a negative co-variance between inevitability and redistributive preferences. These results are consistent with the idea that the impact of the international information treatment is driven by the mere fact of viewing the lower inequality levels in other countries, and not by the format (i.e. a ladder) or index (income ratio) used.

Finally, a plausible alternative explanation for our results could be that, by presenting lower levels of inequality in other countries, the international treatment may point out South African exceptionality in its history of explicit racial discrimination. This may trigger the memory of grievances associated to past racial policies, which could affect demand for redistribution. This possibility can be investigated by estimating the treatment effects on variables that reflect considerations linked to race. These post-treatment variables are (i) support for a special extra tax on whites and (ii) associating the picture of an affluent house to a "white" as opposed to a "rich" person. ${ }^{25}$ If the international treatment activates grievances associated to historical racially determined inequality, we would expect positive coefficients for the international treatment, larger than the ones for the other treatments. Instead, we find no evidence in support of this. If anything, point estimates suggest a higher effect of the local information treatment on supporting a tax for whites (see Table A3 in Appendix A).

In sum, while acknowledging the limitations of our experimental design, we believe that the evidence presented in this paper points to the relevance of inevitability beliefs for redistributive preferences. Our analysis sheds light on a novel mechanism in the literature on redistribution and calls for an increased focus on inevitability/intractability beliefs as one of the potential missing links in the documented disconnect between concerns for inequality and demand for redistribution.

\section{Concluding remarks}

Beliefs about the inevitability of inequality can be quite pervasive in contexts, such as South Africa, where high inequality is a persistent norm. We show that such beliefs can be influenced by gaining knowledge about lower inequality elsewhere. Participants exposed to this type of information significantly update their views about inevitability and at the same time increase their support for redistributive policies. These effects are present for different population groups and for two survey waves carried a year apart.

Since the treatment effect seems to derive from the mere fact of seeing that inequality in other countries is lower than in South Africa, we believe that the most likely interpretation of the results is that this makes people think that high inequality in South Africa is not a fact of life. The significance of changeability perceptions as a driver of redistributive demands may shed light on why information on inequality per se-i.e. information that is not anchored to comparisons of what is possible-might rather encourage resignation or justification of the status quo. A promising avenue for future research would be to investigate further into the different ways through which inevitability beliefs might affect policy preferences.

Overall, the paper suggests that believing that the situation is impossible to change may play a role in explaining low demand for redistribution in high-inequality contexts. This points to the possibility of a vicious circle generating long-term high inequality. The very persistence of inequality may induce pervasive perceptions of inevitability, which can lead to low demand for redistribution and, ultimately, reinforce persistence.

\section{Appendix A.}

Table A1

Balance test of treatment and control.

\begin{tabular}{|c|c|c|c|c|c|c|}
\hline & Age & Female & Matric & Employed & Informal housing & Receive grant \\
\hline Local Info & $1.039(0.825)$ & $0.010(0.028)$ & $-0.001(0.026)$ & $-0.003(0.027)$ & $0.008(0.026)$ & $0.003(0.028)$ \\
\hline Local Info + Video & $-0.614(0.911)$ & $0.009(0.031)$ & $0.124(0.029)$ & $0.009(0.030)$ & $-0.039(0.029)$ & $0.025(0.031)$ \\
\hline International Info & $0.825(0.952)$ & $-0.012(0.031)$ & $-0.019(0.028)$ & $-0.054 *(0.028)$ & $0.010(0.028)$ & $0.019(0.031)$ \\
\hline International Info + Video & $-0.938(1.213)$ & $0.005(0.041)$ & $-0.015(0.036)$ & $0.019(0.037)$ & $-0.054(0.037)$ & $0.026(0.041)$ \\
\hline Control mean & 38.3 & 0.62 & 0.28 & 0.32 & 0.43 & 0.40 \\
\hline Obs & 2433 & 2445 & 2439 & 2441 & 2445 & 2436 \\
\hline
\end{tabular}

Notes: Coefficients from OLS regressions where each column corresponds to a different dependent variable. Robust standard errors in parentheses. P-values: *** $0.01 ;{ }^{* *} 0.05 ; * 0.10$.

\footnotetext{
23 While these guesses are more extreme at the tips of the distribution - to be expected without the anchoring to other countries - the median guess is again 15 , and around $84 \%$ of respondents underestimated inequality (as compared to $85 \%$ in the international treatment).

24 Because of high standard errors, the differences in the coefficients across rows are statistically insignificant.

25 The introduction of a one-shot extra tax for white South Africans was proposed a few years ago by the Nobel Peace Prize winner Desmond Tutu as a compensation for (dis)advantages resulting from Apartheid-era policies.
} 


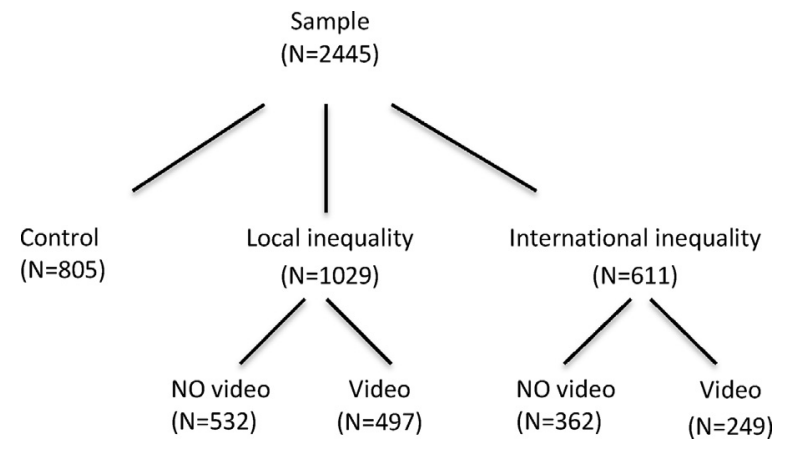

Fig. A1. Survey Design.

\section{Table A2}

Effects of new local information treatment.

\begin{tabular}{lll}
\hline & 1. Inequality inevitable & 2. Summary index \\
\hline Rich/Poor ladder: SA only & $-0.032(0.064)$ & $-0.048(0.123)$ \\
International Info & $-0.074^{*}(0.043)$ & $0.137^{*}(0.074)$ \\
Covariates & Yes & Yes \\
Control mean & 0.55 & 0.02 \\
Obs. & 927 & 901 \\
\hline
\end{tabular}

Notes: Robust standard errors in parentheses. Significance: ${ }^{* * *} 0.01 ;{ }^{* *} 0.05 ;{ }^{*} 0.10$. "Rich/Poor ladder: SA only" is a local treatment that provides the same information as the international treatment except no comparison with other countries is given. Results are based on data from Wave 2 only.

Table A3

Race-related outcomes.

\begin{tabular}{lll}
\hline & 1. Tax whites & 2. House white \\
\hline Local Info & $0.067^{* *}(0.027)$ & $-0.012(0.028)$ \\
International Info & $0.030(0.030)$ & $-0.010(0.030)$ \\
Covariates & Yes & Yes \\
Control mean & 0.36 & 0.40 \\
Obs. & 2362 & 2407 \\
\hline
\end{tabular}

Notes: Robust standard errors in parentheses. Significance: ${ }^{* * *} 0.01 ;{ }^{* *} 0.05 ; * 0.10$. "House white" has value one if respondent answered that an affluent house shown was inhabited by a white person as opposed to a rich one.

\section{Appendix B. Description of Information Treatments}

\section{Local information}

We would like to talk about the differences between the living conditions of poor people and rich people in South Africa. First I would like to ask you how much do you think a typical household earns per month in Gugulethu and how much a typical household earns in Newlands?

This graph shows the monthly income in Philippi, Gugulethu, Camps Bay, and Newlands. As you can see, the monthly income in Gugulethu is about 1,700, in Newlands it is about 30,000 Rand.

Monthly Income

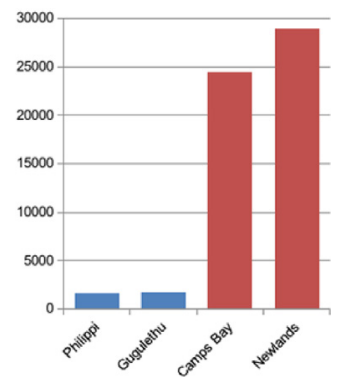


We will now also show you differences in what people own in these neighborhoods.

First, we will show you ownership of cars.

\section{Cars}

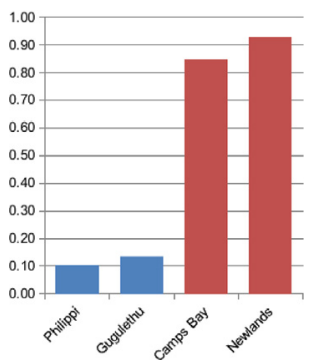

Now, we will show you ownership of washing machines

\section{Washing Machines}

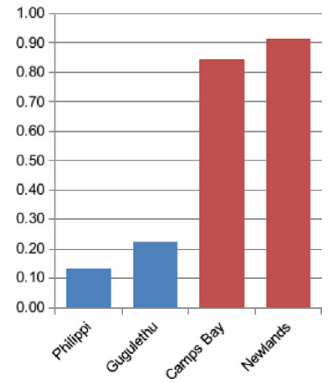

Now, we will show you ownership of computers.

\section{Computers}

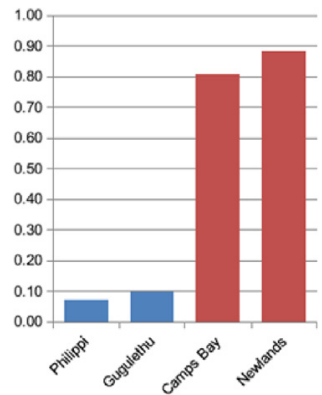

Q: Are you surprised by the differences between Newlands and Gugulethu in ownership of these household goods?

Note that this is an example of the local information treatment provided to one third of respondents. Another third of respondents were presented with differences across three types of neighbourhoods (Gugulethu/Philippi -Athlone/Mitchells Plain - Camps Bay/Newlands), and the last third with only the difference between Athlone/Mitchells Plain and Camps Bay/Newlands.

\section{International information}

We would now like to show you some information about the income differences in South Africa in comparison to other countries.

Here are two examples, India and Mozambique (Note: The graph below is shown for only India and Mozambique. Fieldworkers are instructed to explain intuitively the 5 steps as quintiles of the distribution).

In India the ladder is short, this means that the gap between the rich and the poor is not so big: In India, the rich earn 5 times more than the poor. In Mozambique, the ladder is longer, the rich are further away from the poor. The rich earn about 10 times more than the poor.

Here are some more examples of ladders in other countries. In Zimbabwe, the ladder is quite long, but in Holland it is quite short. (Note: the ladder is shown for all countries except South Africa (i.e. India, Mozambique, US, Zimbabwe, Holland, Malawi)

How long do you think the ladder is in SA?

You said [respondent's guess]. Actually, the ladder looks like this. In South Africa the rich earn more than 20 times the income of poor people, the ladder is very long. 


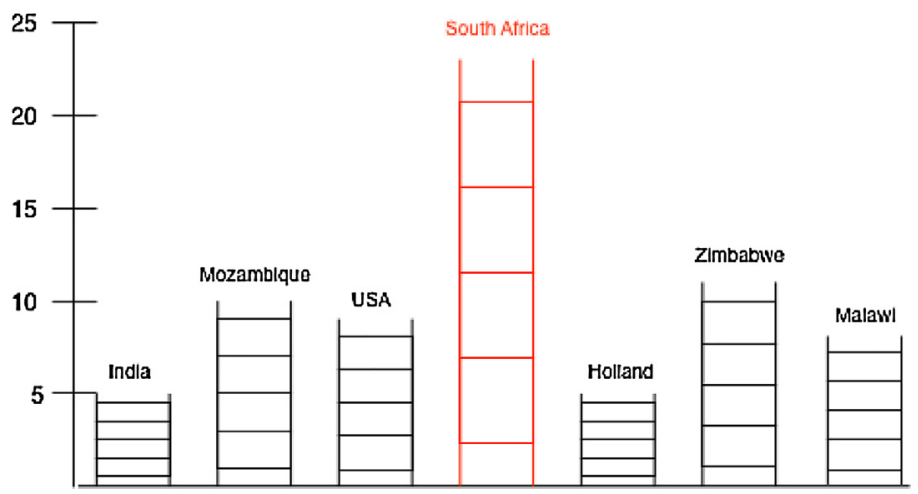

Source: Data for this graph were taken from the 2007-2008 Human Development Report (Table 15). They represent the income (or expenditure) of the 20 per cent richest divided by the income (expenditure) of the 20 per cent poorest in the respective country.

Rich-poor: SA only

We would now like to show you some information about the income differences in South Africa.

[Show SA ladder from international treatment, but without labelling the y axis]

Here is a ladder that shows how big the difference between the rich and the poor is in South Africa. The rich are at the top and the poor are at the bottom. How long the ladder is tells you how much the rich earn compared to the poor.

Q: "In your opinion, how many times more do the rich earn what the poor earn in South Africa?" [capture value]

You said [respondent's guess]. Actually, the ladder looks like this. In South Africa the rich earn more than 20 times the income of poor people, the ladder is very long.

\section{Appendix C. Outcome questions}

\begin{tabular}{|c|c|}
\hline inq-problem & Do you think the gap between rich and poor is a serious problem in South Africa? \\
\hline big & $\begin{array}{l}\text { Some people propose a new government grant called the Basic Income Grant. This is a grant to all South Africans. This } \\
\text { would be different from existing social grants like the old age pension or the child support grant, because everybody } \\
\text { would get it. Do you support the introduction of a Basic Income Grant? }\end{array}$ \\
\hline tax_top & $\begin{array}{l}\text { In South Africa, people must pay taxes depending on their income. Rich people pay about one third of their income as } \\
\text { taxes. For example, somebody who makes R60,000 per month pays R20,000 in taxes and keeps R40,000 for himself. } \\
\text { Do you think RICH people should pay more, less or the same taxes? }\end{array}$ \\
\hline action_note & If you feel strongly about the Basic Income Grant or taxes for the rich, you can take an action to express your opinion. \\
\hline sms & $\begin{array}{l}\text { You could send a SMS to your ward councillor. The way you can do this through our study is to send a SMS to the } \\
\text { coordinator of our study and after we are done with all the interviews, we will send a message to your councillor } \\
\text { telling him which policies people in our study support. We will not tell him your name, just how many people in our } \\
\text { study shared your opinion. Would you like to send a SMS to express your opinion about any of these policies? }\end{array}$ \\
\hline petition & $\begin{array}{l}\text { You can sign a petition expressing your opinion. At the end of our study, we will forward this petition to South African } \\
\text { politicians letting them know which policies people in our study support. We will not tell them your name, just how } \\
\text { many people in our study shared your opinion. Would you like to sign a petition? }\end{array}$ \\
\hline petition taxes1 & $\begin{array}{l}\text { PETITION SUPPORTING AN INCREASE IN TOP MARGINAL TAX RATE Rich people in South Africa should contribute more } \\
\text { to helping people get out of poverty. I support an increase of taxes for people earning more than } 50.000 \text { Rand per } \\
\text { month. This money should be used to help poor people. }\end{array}$ \\
\hline petition taxes 2 & $\begin{array}{l}\text { PETITION SUPPORTING A DECREASE IN TOP MARGINAL TAX RATE Rich people work hard for their income. I support a } \\
\text { DECREASE of taxes for people earning more than } 50.000 \text { Rand per month because effort should be rewarded in South } \\
\text { Africa. }\end{array}$ \\
\hline petition_big_yes & $\begin{array}{l}\text { PETITION SUPPORTING THE INTRODUCTION OF A BASIC INCOME GRANT. Many South Africans are unemployed and } \\
\text { struggle to make a living. A basic income grant would help them to make ends meet. I support the introduction of a } \\
\text { new basic income grant. }\end{array}$ \\
\hline petition_big_no & $\begin{array}{l}\text { PETITION AGAINST THE INTRODUCTION OF A BASIC INCOME GRANT. Government grants should be reserved for } \\
\text { people who really need them such as old people and children. The basic income grant would deter people from } \\
\text { looking for a job. I am against the introduction of a basic income grant. }\end{array}$ \\
\hline tax_white & Some people say that WHITE South Africans should pay a special tax in addition to their normal taxes. Do you agree? \\
\hline tax_gen & $\begin{array}{l}\text { Government officials often complain that there is not enough money to improve public infrastructures like schools, } \\
\text { roads, or sanitation. Do you think taxes should be higher so that the government has more money to improve this? }\end{array}$ \\
\hline deserve & Do you think that the rich in South Africa deserve their high incomes? \\
\hline gov_res & $\begin{array}{l}\text { Do you think that the government should take more responsibility to ensure that everyone is provided for or that } \\
\text { people should take more responsibility to provide for themselves? Choose a number on a scale from } 1 \text { to } 10 \text { to show } \\
\text { how much you agree with these statements, where } 1 \text { means that the government should provide for people and } 10 \\
\text { means that people should provide for themselves. }\end{array}$ \\
\hline
\end{tabular}


choice

cash

grant

inq_inevitable

politicians_care

house
Imagine that a politician gives you the following choice: 1) get R150 in cash today, 2) the government introduces a new grant that gives R50 per month to residents of this neighbourhood next year, 3 ) the government spends money to improve the hospitals and clinics in your neighborhood.

Could you tell me why you prefer the R150 in cash? Answers: 1) I need the money now, 2) I don't trust that the government would keep the promise to introduce the grant or improve hospitals, 3) Other...

Could you tell me why you chose the R50 grant? Answers: 1) I think that the government should solve directly the financial problems of people like me, 2) I'm not sure that the hospitals would really be improved, 3) Other... Do you think that the large gap between rich and poor in South Africa is inevitable? - it's a fact of life || could be made smaller

Do you think that making the gap between the rich and the poor smaller is important to South African political leaders?

Please have a look at this picture. What type of person do you think lives in this house? Answers (order randomized): 1) A rich person, 2) A white per- son, 3) Other. .

\section{Appendix D. Supplementary data}

Supplementary data associated with this article can be found, in the online version, at https://doi.org/10.1016/ j.jebo.2017.12.013.

\section{References}

Alesina, Alberto, Giuliano, Paola, 2011. Preferences for redistribution. In: Heffetz, Ori, Frank, Robert H., Benhabib, Jess, Bisin, Alberto, Jackson, Matthew (Eds.), Handbook of Social Economics. Elsevier, North Holland, pp. 93-132.

Alexander, Peter, 2010. Rebellion of the poor: South Africa’s service delivery protests-a preliminary analysis. Rev. Afr. Polit. Econ. 37 (123), $25-40$.

Bauhr, Monika, Grimes, Marcia, 2014. Indignation or resignation: the implications of transparency for societal accountability. Governance 27 (2), $291-320$.

Benabou, Roland, Ok, Efe, 2001. Social mobility and the demand for redistribution: the POUM hypothesis. Q. J. Econ. 116 (2), $447-487$.

Bourguignon, François, Ferreira, Francisco H.G., Walton, Michael, 2007. Equity, efficiency and inequality traps: a research agenda. J. Econ. Inequal. 5 (2), 235-256.

Chetty, Raj, Friedman, John, Hilger, Nathaniel, Saez, Emmanuel, Schanzenbach, Dian W., Yagan, Danny, 2011. How does your kindergarten classroom affect your earnings? Evidence from project STAR. Q. J. Econ. 126, 1593-1660.

Clingingsmith, David, Khwaja, Asim I., Kremer, Michael, 2009. Estimating the impact of the hajj: religion and tolerance in Islam's global gathering. Q. J. Econ. 124 (3), 1133-1170.

Cruces, Guillermo, Perez-Truglia, Ricardo, Tetaz, Martin, 2013. Biased perceptions of income distribution and preferences for redistribution: evidence from a survey experiment. J. Public Econ. 98, 100-112.

De Juan, Alexander, Wegner, Eva, 2017. Social inequality, state-centered grievances, and protest: evidence from South Africa. J. Conflict Resol., 1-28.

Druckman, James N., 2001. On the limits of framing effects: who can frame? J. Polit. 63 (4), 1041-1066.

Folkman, Susan, Moskowitz, Judith Tedlie, 2004. Coping: pitfalls and promise. Annu. Rev. Psychol. 55, 745-774.

Goñi, Edwin, Humberto López, J., Servén, Luis, 2011. Fiscal redistribution and income inequality in Latin America. World Dev. 39 (9), $1558-1569$.

Gottlieb, Jessica., 2016. Greater expectations: a field experiment to improve accountability in Mali. Am. J. Polit. Sci. 60, $143-157$.

Johnson, India R., Fujita, Kentaro, 2012. Change we can believe in. Using perceptions of changeability to promote system-change motives over system-justification motives in information search. Psychol. Sci. 23 (2), 133-140.

Jost, John T., Pelham, Brett W., Sheldon, Oliver, Sullivan, Bilian Ni, 2003. Social inequality and the reduction of ideological dissonance on behalf of the system: evidence of enhanced system justification among the disadvantaged. Eur. J. Soc. Psychol. 33 (1), 13-36.

Jost, John T., Banaji, Mahzarin R., Nosek, Brian A., 2004. A decade of system justification theory: accumulated evidence of conscious and unconscious bolstering of the status quo. Polit. Psychol., 881-919.

Karadja, Mounir, Möllerström, Johanna, Seim, David, 2017. Richer (and holier) than thou? The effect of relative income improvements on demand for redistribution. Rev. Econ. Stat. 99 (2), 201-212.

Kaufman, Robert., 2009. The political effects of inequality in Latin America: some inconvenient facts. Comp. Polit. 41 (3), 359-379.

Kenworthy, Lane, McCall, Leslie, 2008. Inequality, public opinion and redistribution. Socio-Econ. Rev. 6 (1), $35-68$.

Kling, Jeffrey R., Liebman, Jeffrey B., Katz, Lawrence F., 2007. Experimental analysis of neighborhood effects. Econometrica 75, 83-119.

Kuziemko, Ilyana, Norton, Michael I., Saez, Emmanuel, Stantcheva, Stefanie, 2015. How elastic are preferences for redistribution? Evidence from randomized survey experiments. Am. Econ. Rev. 105 (4).

Leibbrandt, Murray, Woolard, Ingrid, Finn, Arden, Argent, Jonathan, 2010. Trends in South African Income Distribution and Poverty Since the Fall of Apartheid. OECD, Paris.

Leibbrandt, Murray, Eva Wegner and Arden Finn. 2011. The policies for reducing income inequality and poverty in South Africa. SALDRU Working Paper (64).

Meltzer, Allan H., Richard, Scott F., 1981. A rational theory of the size of government. J. Polit. Econ. 89 (6), 914-927.

Smith, Craig A., Lazarus, Richard S., 1990. Emotion and adaptation. In: Pervin, L.A. (Ed.), Handbook of Personality: Theory and Research. Guilford, New York, pp. 609-637.

Tausch, Franziska, Potters, Jan, Riedl, Arno., 2013. Preferences for redistribution and pensions. What can we learn from experiments? J. Pension Econ. Finance 12, 298-325.

Trump, K., 2017. Income inequality influences perceptions of legitimate income differences. Brit. J. Polit. Sci., 1-24, http://dx.doi.org/10.1017/S0007123416000326.

Van der Toorn, Jojanneke, Feinberg, Matthew, Jost, John T., Kay, Aaron C., Tyler, Tom R., Willer, Robb, Wilmuth, Caroline, 2015. A sense of powerlessness fosters system justification: implications for the legitimation of authority, hierarchy, and government. Polit. Psychol. 36 (1), 93-110. 